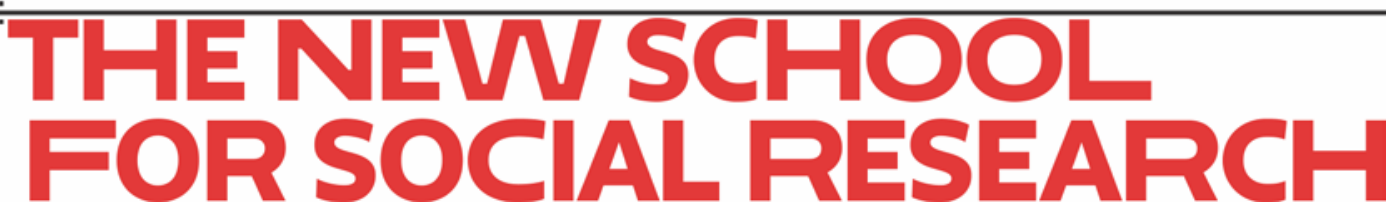

Mark Setterfield

\title{
Long-run variation in capacity utilization in the presence of a fixed normal rate
}

February 2017

Working Paper 04/2017

Department of Economics

The New School for Social Research 


\title{
Long-run variation in capacity utilization in the presence of a fixed normal rate
}

\author{
Mark Setterfield*
}

February 10, 2017

\begin{abstract}
We develop a generic Kalecki-Robinson model of growth that, subject to different closures, illustrates the different channels through which the economy can adjust to a change in demand conditions in the long run. The closures are shown to have different implications for the behaviour of the rate of capacity utilization and hence whether and how the economy achieves a "fully-adjusted position" (equalization of the actual and normal rates of capacity utilization). Assuming that the normal rate of capacity utilization is exogenously fixed, it is then shown that variation in the actual capacity utilization rate can nevertheless occur - at least within limits - without triggering "Harrodian instability". This result emanates from a discontinuity in the investment function that is grounded in Harrod's own macrodynamics, so that it is ultimately the combination of Harrodian and Kaleckian dynamics that gives rise to long-run variations in the actual rate of capacity utilization in the presence of a fixed normal rate. Aggregate and industry-level US capacity utilization data are then used to calculate possible bands within which the rate of capacity utilization may vary without triggering Harrodian instability. A key finding is that the conditions necessary for the latter appear to be relatively rare.
\end{abstract}

JEL codes: E11, E12, O41

Keywords: Normal rate of capacity utilization, Harrodian instability, Kaleckian growth theory.

${ }^{*}$ Department of Economics, New School for Social Research; mark.setterfield@newschool.edu. An earlier version of this paper was presented at the Workshop on Economic Growth and Distribution, State University of Santa Cruz (UESC), Ilhéus, Brazil, March 10-11, 2016, and at the CEPN, Université Paris XIII, Sorbonne Paris Cité, Paris, France, June 3, 2016. Particular thanks are due to Joana David Avritzer for research assistance and to Marc Lavoie for his helpful comments on an earlier draft. Any remaining errors are my own. 


\section{Introduction}

A substantial literature connects the relatively rapid growth of the US economy during the "Great Moderation" (1990-2007) to aggressive increases in household indebtedness (Palley, 2002; Cynamon and Fazzari, 2008, Brown, 2008; Barba and Pivetti, 2009; Wisman, 2013, Setterfield, 2013). This is hypothesized to have offset the otherwise negative impact on consumption spending of stagnant wage growth and rising income inequality during the same period. According to this view, redressing the dramatic increases in income inequality that have characterized recent US experience is critical to restoring robust and sustainable growth in the US economy.

The analysis outlined above draws on a long-standing result in Post-Keynesian macrodynamics which shows that redistributing income away from wages is inimical to growth. The basis for this result is controversial, however. A necessary condition for growth to increase in response to a rise in the wage share of income is that the rate of capacity utilization is variable in the long run. According to Classical (Marxian) and neo-Keynesian growth theory, the rate of capacity utilization cannot vary in the long run, because it is anchored by a fixed "normal" rate of capacity utilization on which firms base their investment plans $\mathrm{I}^{1}$ Post-Keynesians claim that capacity utilization can vary in the long run, even when there exists a normal rate of capacity utilization, because of "hysteresis" in the normal rate: the latter - understood as a historically-grounded rule of thumb - is thought to rise and fall with the actual rate of capacity utilization (Lavoie, 1995, 1996, 2010; Dutt, 1997, 2010; Cassetti, 2006; Commendatore, 2006) . $^{2}$ Classical macroeconomists typically counter that the hystere-

\footnotetext{
${ }^{1}$ This criticism of Post-Keynesian macrodynamics is longstanding. See, for example, Committeri (1986); Auerbach and Skott (1988).

${ }^{2}$ An alternative argument, advanced originally by Lavoie (1992, pp.417-21) and Lavoie (2002, 2003) and developed by Dallery and van Treeck (2011), is that firms pursue multiple, potentially competing, objectives, and that this permits departure of the actual rate of capacity utilization from its normal rate even in the long term. See Hein et al. (2012) for a survey of the Post Keynesian responses to the Classical/neo-Keynesian position.
} 
sis argument contradicts the very purpose of the normal rate, so that the Post-Keynesian approach lacks proper behavioral foundations.

The purpose of this paper is to show how long-run variation in the capacity utilization rate can arise as the result of satisficing behavior on the part of firms in response to a decision-making environment of fundamental uncertainty. This occurs even when firms adhere to a fixed (ahysteretic) normal rate of capacity utilization, because satisficing firms will tolerate - within limits - deviation of the observed values of variables from their preferred or target values without modifying their behavior $3^{3}$ The argument advanced is not new, having previously been entertained by Dutt (1990, pp.58-59) and Lavoie (1992, pp.327-32, 417-22), and developed (by appeal to G.L.S. Shackle's concept of potential surprise) by Dutt (2010) 4 $^{4}$ Beyond its further codification of the argument, one of the principle contributions of this paper is its association of limited variation in the capacity utilization rate with the thinking of Harrod himself $]^{5}$ so that it is the combination of Harrodian and Kaleckian insights that furnishes variability in the capacity utilization rate even in the presence of a fixed normal rate. We therefore take issue with authors such as Palumbo and Trezzini (2003, p.30, n.21) who, in their otherwise sympathetic approach to the ideas developed in this paper, associate Harrod with the idea that "entrepreneurs react immediately to any change in the effective rate of growth - and thus to any over-utilization or under-utilization of capacity - by taking investment or disinvestment decisions that work to adjust the imbalance". This is somewhat ironic, given that Harrod is frequently associated with the neo-Keynesian position according to which a fixed normal rate prohibits long-run variation of the capacity utilization rate (Skott, 2010, 2012; Skott and Ryoo, 2008). A second contribution arises from the paper's attempt to operationalize the theory of a normal range of capacity utilization rates, by iden-

\footnotetext{
$\sqrt[3]{\text { Hein et al. }}$ (2012) associate this type of approach with questioning the notion of a normal rate of capacity utilization. As will become clear, it certainly questions the notion of a fixed normal rate of capacity utilization as a "knife-edge", departure from which will always and everywhere trigger behavioral change by firms.

${ }^{4}$ See Hein et al. (2012, pp.146-8) for an overview of these contributions.

${ }^{5}$ The basic idea is more often associated with Hicks (1974). See, for example, Hein et al. (2012, p.16).
} 
tifying the magnitude of the variation of capacity utilization that firms will deem tolerable, and comparing this with actual variations in the capacity utilization rate. These calculations are performed in both one-sector and multi-industry contexts. The chief finding of this analysis is that the circumstances under which Harrodian instability materializes are relatively rare.

The remainder of the paper is organized as follows. In section 2 , we develop a generic Kalecki-Robinson model of growth that can be subject to different closures and that illustrates the different channels through which the economy can adjust to a change in demand conditions in the long run. The closures have different implications for the behaviour of the rate of capacity utilization and hence what is required in order for the economy to achieve a "fully-adjusted position", in which the actual and normal rates of capacity utilization are equalized. In section 3, we postulate an exogenously fixed normal rate of capacity utilization, but show that variation in the actual capacity utilization rate can nevertheless occur - at least within limits - without triggering "Harrodian instability": the tendency for investment spending and capacity utilization to interact in a self-reinforcing fashion in response to any initial discrepancy between the actual and normal rates of capacity utilization. The result is shown to emanate from a discontinuity in the investment function that is grounded in Harrod's own macrodynamics, so that it is ultimately the combination of Harrodian and Kaleckian dynamics that gives rise to long-run variations in the actual rate of capacity utilization even when the normal rate is exogenously fixed. Section 4 uses both aggregate and industry-level US capacity utilization data to calculate possible bands within which the rate of capacity utilization may vary without eliciting the changes in investment behaviour required to generate Harrodian instability. Section 5 offers some conclusions. 


\section{The "Harrodian instability" debate: reconciling the actual and normal rates of capacity utilization}

According to Hein et al. (2011, 2012), two of the major debates that surround Kaleckian macrodynamics are the issues of Keynesian stability and Harrodian instability. Keynesian stability requires that saving is more responsive to variations in capacity utilization than investment spending. Harrodian instability, meanwhile, involves the tendency for investment spending and capacity utilization to interact in a self-reinforcing fashion in response to any discrepancy between the actual and normal rates of capacity utilization. Assuring the absence of the latter in the long run requires reconciliation of the actual and normal rates of capacity utilization - i.e., achievement of a Classical "fully-adjusted" position. The question then becomes: is this achieved by movement of the actual capacity utilization rate towards a fixed normal rate, or accommodating adjustment of the normal rate of capacity utilization in response to variation in the actual rate?

In order to explore this question in more detail, consider the following "generic" KaleckiRobinson model:

$$
\begin{gathered}
g=\gamma_{1}+\gamma_{2} r \\
r=\pi u \\
g^{s}=s_{\pi} r
\end{gathered}
$$

where $g$ is the rate of accumulation, $r$ is the rate of profits, $\pi$ is the profit share of income, $u$ is the rate of capacity utilization (proxied by the ratio of real output to the capital stock), $g^{s}$ is the rate of accumulation consistent with saving-investment balance, $\gamma_{1}$ and $\gamma_{2}$ are

\footnotetext{
${ }^{6}$ As will become clear below, the two types of adjustment need not be mutually exclusive. See also Hein et al. (2011, pp.595-6).
} 
parameters reflecting the animal spirits of firms, and $s_{\pi}$ is the propensity to save out of profits. Equation (1) is a Robinsonian investment function relating the rate of accumulation to the rate of profit. $7^{7}$ Equation (2) is true by definition, although in the Kaleckian tradition it is commonly referred to as the "pricing equation" on the grounds that the profit share of income is determined by firms' choice of the mark up in a cost-plus pricing procedure. Equation (3) is the Cambridge equation relating the rate of accumulation necessary to equate saving and investment to the saving decisions of capitalist households.

Under the equilibrium conditions $g=g^{s}$, equations (1) and (3) yield:

$$
r=\frac{\gamma_{1}}{s_{\pi}-\gamma_{2}}
$$

Substituting equation (2) into this last expression yields:

$$
\pi u=\frac{\gamma_{1}}{s_{\pi}-\gamma_{2}}
$$

According to equation (4), as animals spirits and hence the parameter $\gamma_{1}$ vary, so, too, does $r=\pi u$. But which is the adjusting variable: $\pi$ or $u$ ?

Consider first the "Robinsonian closure" $u=u_{n}$, where $u_{n}$ denotes the normal rate of capacity utilization. 8 We assume initially that $u_{n}$, which is chosen by firms to insulate them from unforeseen variations in demand, can be taken as given. It therefore follows from (4)

\footnotetext{
${ }^{7}$ Having initially motivated our inquiry by appeal to debate over the paradox of costs, the choice of equation (1) may seem peculiar, since this Robinsonian investment function is incapable in principle of yielding a wage-led growth result. Note, however, that while the paradox of costs is an important motivation for this paper, the focus of analysis is the channels through which disequilibrium adjustment occurs in Kalecki-Robinson type models (prices versus quantities or, alternatively, distributional shares versus the capacity utilization rate). Given the focus of inquiry, the Robinsonian investment function in (1) has been chosen on the grounds that it is both parsimonious and suitable for the purpose at hand. Note further that if we set $\gamma_{1}=\gamma_{0}+\gamma_{3} u$ in equation (1), the result would be a canonical Kaleckian investment function capable of producing a paradox of costs result. In what follows, however, this would add algebra but not additional insight to our analysis.

${ }^{8}$ As noted by Hein et al. (2011, p.593), a hallmark of Cambridge models of distribution, including specifically those of Robinson (1956,1962), is the assumption that the rate of capacity utilization does not vary between steady-state equilibrium configurations.
} 
that:

$$
\pi=\frac{\gamma_{1}}{\left(s_{\pi}-\gamma_{2}\right) u_{n}}
$$

so that variations in animal spirits are absorbed by variations in the profit share according to:

$$
\Delta \pi=\frac{1}{\left(s_{\pi}-\gamma_{2}\right) u_{n}} \Delta \gamma_{1}
$$

In equation (6), an initial improvement in animal spirits that causes investment to exceed saving creates excess demand in the goods market that bids up prices (the fixity of capacity utilization making quantity adjustment impossible).$^{9}$ As prices rise, the value of the real wage falls, effecting a change in the profit share of income (seen on the left hand side of equation (6) consistent with the fact that $\pi=1-w a$ (where $w$ is the real wage and $a$ is the assumed fixed labour:output ratio). Notice that these adjustments are consistent with a rise in the rate of profit in equation 2, as the economy moves along the Classical wage/profit frontier given by $r=\pi u=(1-w a) u_{n}$.

Now consider an alternative "Kaleckian closure", $\pi=\bar{\pi}$. The Kaleckian closure can be considered as emanating from the practice of mark-up pricing by firms, in which prices are set as a fixed mark up over average direct costs of production. Under the Kaleckian closure it follows from (4) that:

$$
u=\frac{\gamma_{1}}{\left(s_{\pi}-\gamma_{2}\right) \bar{\pi}}
$$

so that variations in animal spirits are absorbed by variations in the rate of capacity utiliza-

\footnotetext{
${ }^{9}$ Note that quantity adjustment through variation in the amount of labour employed is ruled out by assumption that variation in the capital:labour ratio is impossible in the absence of technological change. In other words, the supply side implicit in our generic Kalecki-Robinson model is characterized by a Leontieff production technology.
} 
tion according to:

$$
\Delta u=\frac{1}{\left(s_{\pi}-\gamma_{2}\right) \bar{\pi}} \Delta \gamma_{1}
$$

In equation (8), an initial improvement in animal spirits that causes investment to exceed saving creates excess demand in the goods market that increases output, the fixity of prices implied by mark-up pricing making price adjustment impossible. This increase in output brings about the change in capacity utilization seen on the left hand side of equation (8). Notice that these adjustments are consistent with a rise in the rate of profit in equation (2), as the Classical wage/profit frontier given by $r=\pi u=(1-\bar{w} a) u$, where $\bar{w}=(1-\bar{\pi}) / a$, now rotates in response to a rise in $u$.

The two adjustment mechanisms associated with the Robinsonian and Kaleckian closures are depicted in Figure 1. Note that these adjustment mechanisms need not be mutually exclusive: it is possible, in principle, to observe both $\Delta \pi$ and $\Delta u$ as a result of simultaneous adjustment of prices and quantities (Lavoie, 2010). This is depicted by the arrows illustrating movement away from both $u_{n}$ and $\bar{\pi}$ in Figure 2 .

But if adjustment in response to excess demand involves any lasting variation in $u$ so that $u \neq u_{n}$ in the long run - i.e., the system does not achieve a Classical fully-adjusted position - then the system is vulnerable to Harrodian instability (see, for example, Hein et al. (2011, p.592)). According to this argument, any initial discrepancy between the actual and normal rates of capacity utilization will trigger an increase in investment (designed to increase capacity and hence resolve the discrepancy between the actual and normal rates of capacity utilization) that will further increase the actual rate of capacity utilization, increasing the difference between the actual and normal rate, and so on. In other words, investment spending and capacity utilization will interact in a self-reinforcing fashion - unless the discrepancy between the actual and normal rates of capacity utilization is somehow 


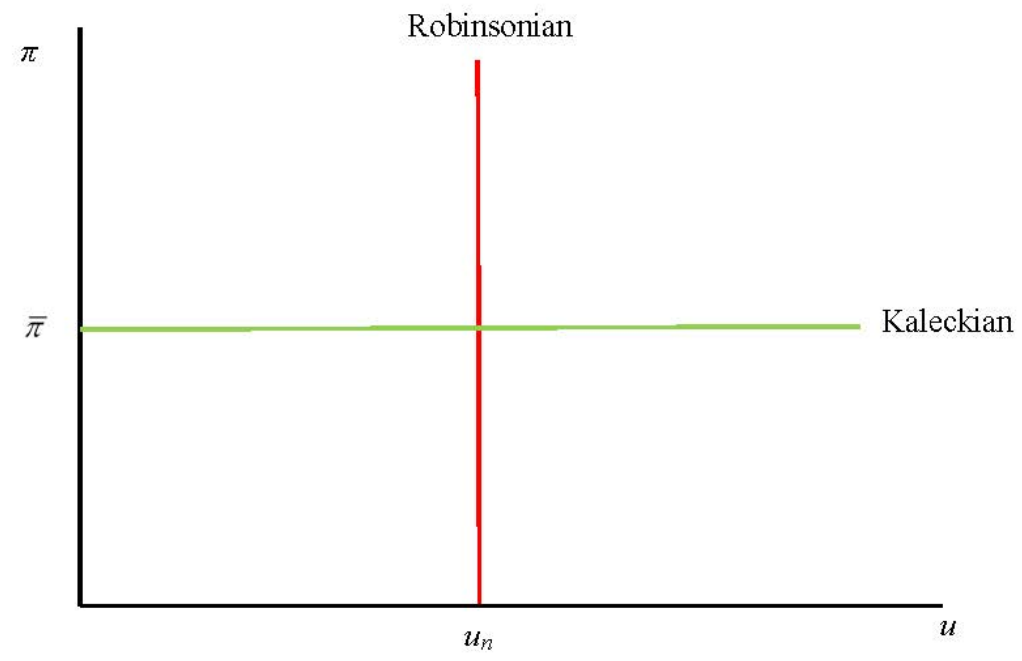

Figure 1: The Robinsonian and Kaleckian Adjustment Mechanisms

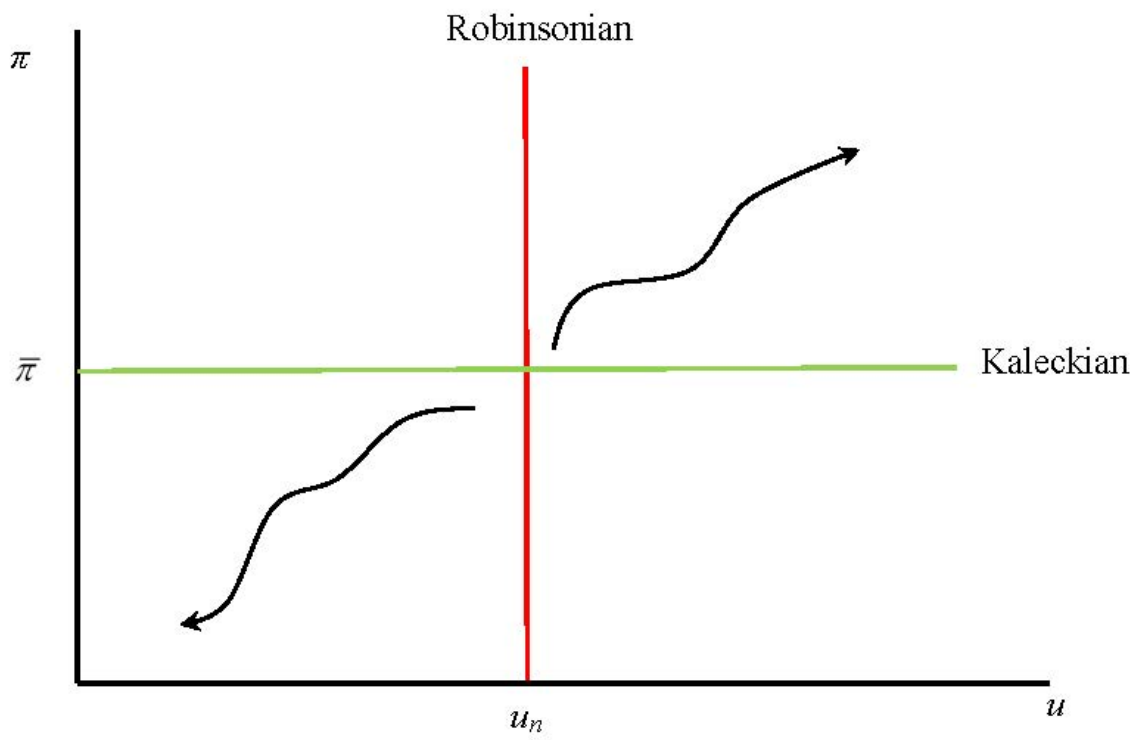

Figure 2: Simultaneous Price and Quantity Adjustment 
resolved. In terms of the generic Kalecki-Robinson model developed in this section, under the Kaleckian closure, equation (8) describes not a once-over change in capacity utilization, but a cumulative series of changes in $u$ and $\gamma_{1}$ in response to an initial change in animal spirits. The upshot of all this is that operating under the Kaleckian closure, the generic Kalecki-Robinson model provides an incomplete understanding of macrodynamics.

According to some Kaleckians (see, for example, Lavoie (1995, 1996); Dutt (1997, 2009)), the solution to this eventuality lies in first recognizing that the "Robinsonian closure" actually stipulates that $u_{n}=\bar{u}_{n}$. But suppose, instead, we write:

$$
\dot{u}_{n}=\alpha\left(u-u_{n}\right)
$$

Equation (9) not only suffices to ensure achievement of a fully adjusted position, but is also compatible with the Kaleckian closure (and hence long run variation in the rate of capacity utilization). Suppose that we begin with $u=u_{n 1}$ in Figure 3. Now suppose that an improvement in animal spirits increases $u$ in accordance with equation (7), so that $u>u_{n 1}$. According to equation (9), this last result will increase the normal rate of capacity utilization itself until $u=u_{n}$ - which outcome is depicted at $u_{n 2}$ in Figure 3. The normal rate of capacity utilization can now be thought of as displaying hysteresis, as a result of which, following an initial increase in capacity utilization, the system attains a new fully-adjusted position at a permanently higher rate of capacity utilization.

Classical and neo-Keynesian authors remain unconvinced by the idea that $u_{n}$ is hysteretic, however. According to Skott (2012, pp.117-124), for example, equation (9) is mechanistic and lacks proper behavioural foundations. Hence the purpose of $u_{n}<1$ is to insulate firms against the vagaries of demand conditions in an environment of uncertainty where, for want of capacity, it is also disadvantageous to lose sales and hence relative firm size, monopoly power, and control over the external market environment. It therefore makes no sense to 


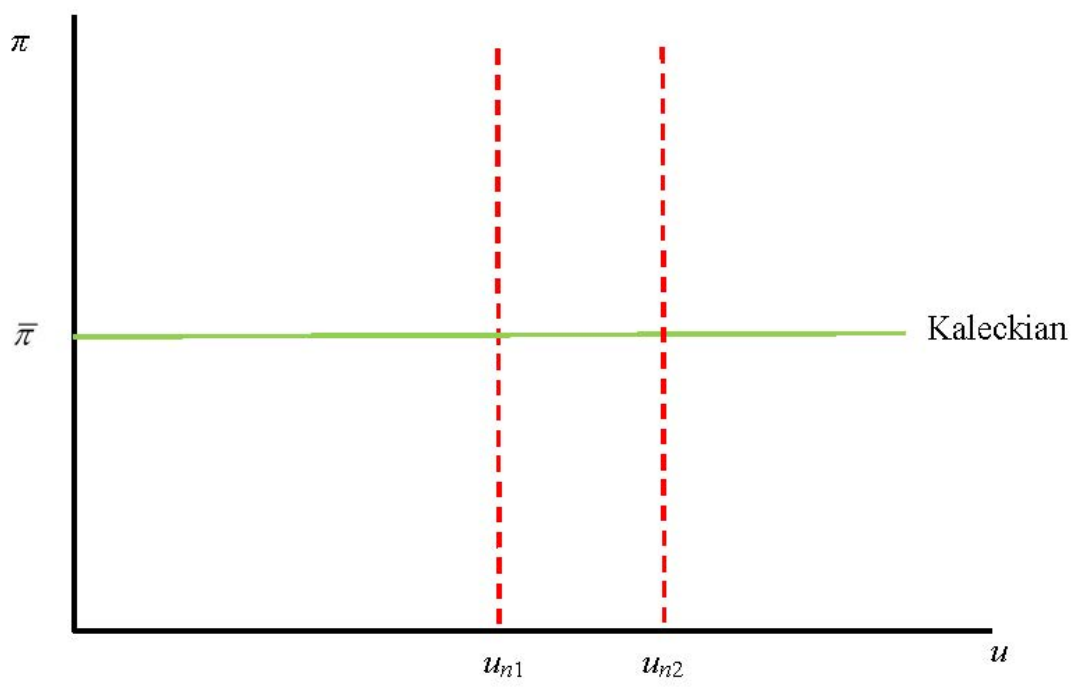

Figure 3: Hysteresis in the Normal Rate of Capacity Utilization

allow $u_{n}$ to vary in such an accommodating fashion in response to changes in $u$. Attainment of a fully adjusted position - and avoidance of Harrodian instability in the long run - must be achieved by means other than adjustment of $u_{n}$.

Suppose, then, that we eschew equation (9) in favor of the "true" Robinsonian closure $u=\bar{u}_{n}$. Does this rule out long run variation in the rate of capacity utilization? In the following section, we will demonstrate that it need not, and that a marriage of Harrodian and Kaleckian thinking brings about this result.

\section{Kaleckian results: a Harrodian approach}

Central to the argument advanced in this section is the claim that the contributions of Harrod 1939, 1948, 1973) himself are of crucial significance to debate about Harrodian instability in Kaleckian macrodynamics ${ }^{10}$ Of particular importance is a feature of Harrod's analysis that

\footnotetext{
${ }^{10}$ The analysis here draws on Setterfield 2015 , who applies the same ideas to furnish an explanation of time variation in the size of the multiplier.
} 
distinguishes his instability principle from the (in)famous "knife edge" property attributed to it by Solow (1956) (on which see also Kregel (1980), Asimakopulos (1991, pp.161-4) and Halsmayer and Hoover (2015)). As recounted by Asimakopulos (1991, pp.161), a subtle but important qualification to the operation of the instability principle involves the reaction time required for firms to respond to discrepancies between actual and expected events.11 For Harrod (1939), departures of the actual from the warranted rate of growth that do not exceed the reaction time (six months) will not trigger changes in investment behaviour. By the time of his reply to Robinson (1970), Harrod (1970) had expanded upon this theme, arguing that the size (as well as the duration) of discrepancies between actual and expected outcomes plays a central role in the operation of the instability principle, which is therefore less like a "knife edge" than a "shallow dome". Hence in his reply to Robinson (1970), Harrod writes:

I have argued that an equilibrium growth path is normally unstable ... If it is on a knife-edge a very tiny push would serve to push it away; but it would also be an unstable equilibrium if it were at the top of a shallow dome. Then a much larger push would be needed to set it moving. (Harrod, 1970, p.740)

Harrod goes on to associate the size of this "larger push" with a variety of factors including conventions and various other factors associated with the formation of expectations, concluding that empirical study is required to ascertain the precise size of a "larger push". Harrod embellishes this thinking in his final book on macrodynamics, wherein he argues that:

if they [deviations of the actual from the warranted rate] are of moderate dimensions, I would not suppose that they would bring the instability principle into operation. That is why I so much object to the knife-edge idea. It requires a fairly large deviation ... to bring the instability into play. (Harrod, 1973, p.33) $)^{12}$

\footnotetext{
${ }^{11}$ Note that in Harrodian dynamics, discrepancies between actual and expected events can be associated with departures of the actual rate of growth from its warranted (equilibrium) rate, and hence departures of the actual rate of capacity utilization from its normal rate.

${ }^{12}$ In Harrod (1973, p.32), the preferred metaphor for the instability principle is a "grassy slope" rather than a "shallow dome".
} 
The investment behaviour envisaged by Harrod bears comparison to a satisficing heuristic of the sort envisaged by Simon (1955, 1956), in which explicit acknowledgment of the limits to their foresight means that firms are unlikely to be provoked into behavioural change by only modest and/or brief discrepancies between the actual and expected rate of growth, and hence the actual and normal rate of capacity utilization 13 Instead of adjustment resting on a "knife edge" created by a specific value of the normal rate, a rule of thumb is developed that specifies a tolerable interval of variation around the specific value. Variations in actual capacity utilization that lie outside this tolerable interval will attract attention and provoke behavioural change. Variations within the bounds prescribed by the interval will, however, be ignored. More generally, Harrod's thinking suggests that investment behaviour is unlikely to vary continuously, but is instead susceptible to discrete variation depending on where macroeconomic outcomes lie with respect to the boundaries of conventionally-defined tolerable intervals around any expected, normal, or target value of a variable that is used to guide behaviour in an environment of uncertainty.

What are the implications of these ideas for the Harrodian instability debate? The main claim advanced here and developed in what follows is that a mixture of standard Kaleckian macrodynamics and Harrod's "satisficing" approach to the revision of investment decisions provides a basis for understanding variation in the actual rate of capacity utilization even in the presence of a fixed normal rate. Hence in the Classical/neo-Keynesian tradition: ${ }^{14}$

\footnotetext{
${ }^{13}$ Satisficing behaviour can result from cognitive limitations in an external environment that is otherwise knowable in principle. It is perhaps more consistent with the foundations of modern Post-Keynesian macrodynamics, however, to regard satisficing as a necessary expedient brought about by characteristics of the external environment itself - namely, that it is unknowable in principle and so imposes fundamental uncertainty upon decision makers. On this basis, the Harrodian foundations of long-run variation in the capacity utilization rate explored in this paper, and those grounded in Shackle's concept of potential surprise (as explored by Dutt (2010)), are revealed as two sides of the same coin. In other words, in order to find a behaviourally-grounded basis for responding to Classical/neo-Keynesian critiques of Kaleckian macrodynamics based on appeal to the phenomenon of Harrodian instability, one need look no further than Harrod himself!

${ }^{14}$ See Skott and Ryoo (2008); Dutt (2010); Skott (2012).
} 


$$
\dot{g}=g\left(u-\bar{u}_{n}\right)
$$

This suggests that firms will increase their rate of accumulation in the event that $u>$ $\bar{u}_{n}$ in an attempt to increase available capacity and so lower the actual rate of capacity utilization towards the normal rate. If this behaviour has a larger effect on the supply side (available capacity) than on the demand side (utilized capacity), then the actual rate of capacity utilization will automatically fall towards the normal rate and the economy will achieve a fully-adjusted position ${ }^{15}$ Otherwise, Harrodian instability will prevail, unless an auxiliary mechanism (such as the Robinsonian adjustment of prices and hence the profit share) reconciles the steady state equilibrium of the system with the fixed normal rate, $\bar{u}_{n} .^{16}$ Harrodian instability is illustrated in Figure 4 below, in which the $g$ and $g^{s}$ schedules are derived from substitution of equation (2) into equations (1) and (3) (as a result of which both $g$ and $g^{s}$ are depicted as functions of $u$ ). Starting at the fully adjusted position $g^{*}$, $\bar{u}_{n}$, an improvement in animal spirits displaces the $g$ schedule upwards to $g^{\prime}$, establishing a

\footnotetext{
${ }^{15}$ This is effectively what is achieved by the Hicksian stock-flow investment adjustment mechanism posited by Shaikh (2009). Hein et al. (2011) are critical of this adjustment mechanism on the grounds of its informational requirements: firms must correctly anticipate output growth in the next period, so that the model effectively involves myopic perfect foresight (see also Skott (2010, fn 28)). It might be argued that myopic perfect foresight is a plausible (and useful) first approximation of forecasting in heterodox macrodynamics (Flaschel et al., 1997). Even this mild form of rational expectations is, however, known to be immediately destructive of Harrodian instability, which can only be propagated if there is some adaptation of expectations to expectational error (Franke, 2015). In this sense, rather than demonstrating a mechanism that results in the taming of Harrodian instability, it can be argued that in Shaikh (2009) the very source of Harrodian instability is ruled out by assumption (see also Skott (2010, fn 28)). The assumption in question, meanwhile, cannot be justified on the grounds that "[s]ince both Keynesian and Harrodian theories assume that demand equals supply over the short run (Asimakopulos, 1991, pp.40-1), they implicitly assume that output successfully targets expected demand" (Shaikh, 2009, p.465, emphasis in original). This argument conflates the ex post realization of expectations (which can be the outcome of a Harrodian-instability-producing process of adaptation) with their ex ante realization (due to myopic perfect foresight). But these are not the same thing. The realization of expectations is an equilibrium condition, whereas the rational expectations hypothesis is a behavioural postulate, and of course the former does not imply the latter (as demonstrated by models in which expectations are adaptive). The logic of Shaikh's analysis based on his assumption of myopic perfect foresight is unassailable, but the assumption itself (and the purported basis for making it) are questionable.

${ }^{16} \mathrm{~A}$ variety of other mechanisms have been proposed that achieve the same end. See Hein et al. (2011) for a survey.
} 
new equilibrium at $g^{\prime}, u^{\prime}$. In the canonical Kaleckian model, this would be the end of the story: $g^{\prime}, u^{\prime}$ would prevail as the new, long-term equilibrium of the system. But with the Classical/neo-Keynesian adjustment mechanism $\dot{g}=g\left(u-\bar{u}_{n}\right)$, there will be further upward shifts in the $g$ schedule (to $g^{\prime \prime}$ and subsequently - as indicated by the arrow in Figure 4 beyond). These shifts in the $g$ schedule are the manifestation of Harrodian instability, the effects of which will continue unabated unless the operation of some other mechanism causes $u$ to adjust towards $\bar{u}_{n}{ }^{17}$

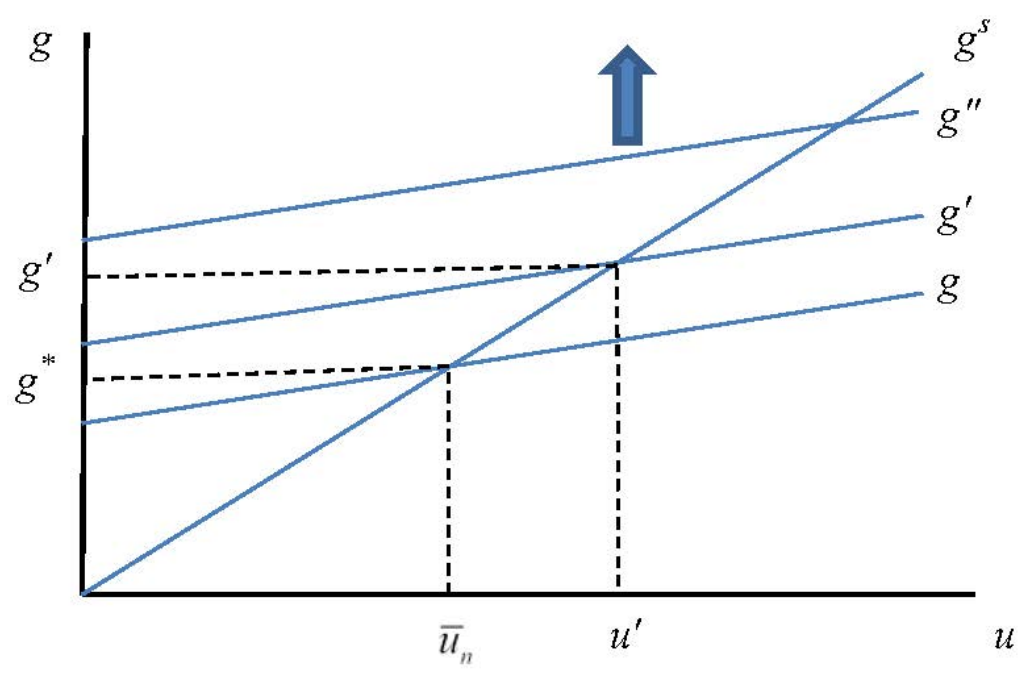

Figure 4: Harrodian Instability in the Kalecki-Robinson Model

Suppose, however, that in the spirit of Harrod (and following Simon (1955, 1956)), firms are satisficers for whom there is a range of variation in $u$ about $\bar{u}_{n}$ that is deemed acceptable, so that variation in $u$ within this range is thought unworthy of behavioural response 18 Under

\footnotetext{
${ }^{17}$ Of course, Harrodian instability may also be checked by the fact that we must observe $0 \leq u \leq 1$.

${ }^{18}$ As noted, Dutt (2010) motivates the same absence of behavioural response by appeal to Shackle's concept of potential surprise, according to which, under conditions of fundamental uncertainty, decision makers will tolerate some variation in actual events relative to expected events and deem only sufficiently large deviations of actual from expected events - that generate surprise - as worthy of behavioural response. Although he
} 
these conditions, the Classical/neo-Keynesian response is modified so that:

$$
\begin{array}{r}
\dot{g}=0 \text { if }\left|u-\bar{u}_{n}\right|<c \\
\dot{g}=\left(u-\bar{u}_{n}\right) \text { otherwise }
\end{array}
$$

where $c$ is a conventional constant that corresponds to the "moderate dimensions" within which, per Harrod (1970, 1973), the model can depart from its equilibrium (fully-adjusted) position without eliciting a behavioural response from firms. Effectively, the range of values $\bar{u}_{n} \pm c$ involves de facto treatment of the normal rate of capacity utilization as a band rather than a point 19 In terms of the simple Kalecki-Robinson model developed earlier, where variations in animal spirits are accommodated either through $\Delta u$ (the quantity channel) or $\Delta \pi$ (the price channel), we now get:

$$
\Delta u=\frac{1}{\left(s_{\pi}-\gamma_{2}\right) \bar{\pi}} \Delta \gamma_{1}
$$

cites Harrod (1970, p.740) on the distinction between the dynamics of a knife-edge and those of a shallow dome, Dutt does not explicitly connect Harrod's thinking to Kaleckian dynamics in the case where the actual rate of capacity utilization deviates form the normal rate.

${ }^{19}$ Note that, in keeping with our treatment of $c$ as a conventional constant, the band so-described is constant in size. According to Schoder (2012, p.543), if, over time, firms become increasingly confident about their single-valued normal rate of capacity utilization and, as a consequence, ever less tolerant of departures from this normal rate, then the size of the band around the normal rate will diminish and (in the limit) disappear. However, this is true only if the uncertainty perception and awareness that informs firms' confidence (Dequech, 1999) declines monotonically over time. If, however, the variance of the rate of capacity utilization is non-constant and instead "flares up" during crises, then uncertainty perception and awareness, and hence firms' confidence, will likely oscillate (rather than decline monotonically) - as, in consequence, will the value of $c$ and hence the size of the band around $\bar{u}_{n}$. This suggests that although $c$ may not be (indeed, likely is not) time-invariant - so that the range of values of $u$ within which Kaleckian quantity adjustment can occur is non-constant - the essential point that the normal rate of capacity utilization can be treated as a band rather than a point remains intact. Treating this band as constant in size can be thought of as a simplifying first approximation.

Even so, the treatment of this band in the model developed here means that any $\left|u-u_{n}\right| \geq c$ will elicit an investment response. See, however, Trezzini (2016) for scepticism on this point - not least because for investment to respond, $\left|u-u_{n}\right| \geq c$ of sufficient duration may be required. This is consistent with the Harrodian notion of a "reaction period" referred to earlier (on which see, for example, Asimakopulos (1991. chpt.7)). This feature of Harrod's dynamics is not captured by the model developed here. 
if $\bar{u}_{n}-c<u<\bar{u}_{n}+c$, and:

$$
\Delta \pi=\frac{1}{\left(s_{\pi}-\gamma_{2}\right) u_{B_{i}}} \Delta \gamma_{1} \quad, \quad i=U, L
$$

if $u=u_{B_{U}}=\bar{u}_{n}+c$ or $u=u_{B_{L}}=\bar{u}_{n}-c{ }^{20}$ These adjustments are illustrated by movement along the solid "Kalecki-Harrod" schedule in Figure 5. The result is a model in which there can be long-run variation in the rate of capacity utilization a la Kalecki - at least within limits imposed by the tolerable range of departures of $u$ from $\bar{u}_{n}$ conjectured by Harrod even in the presence of a fixed (ahysteretic) normal rate of capacity utilization guiding firms' investment behaviour. This is illustrated in Figure 6. Once again, we begin at the fully adjusted position $g^{*}, \bar{u}_{n}$. An improvement in animal spirit that displaces the $g$ schedule upwards to $g^{\prime}$ will once again establish a new equilibrium at $g^{\prime}, u^{\prime}$. Since $u^{\prime}<\bar{u}_{n}+c$, we will have $\dot{g}=0$ from equation(11), so that $g^{\prime}, u^{\prime} \neq \bar{u}_{n}$ will prevail as the new, long-term equilibrium of the system. When augmented by "proper" (discontinuous) as opposed to "vulgar" (continuous) Harrodian dynamics, the results of the canonical Kaleckian model including the paradox of costs - may once again prevail. ${ }^{21}$

\footnotetext{
${ }^{20}$ Recall that we are depicting long run outcomes, so that there is no possibility of observing $u>\bar{u}_{n}+c$ or $u<\bar{u}_{n}-c$. Adjustment to variations in animal spirits is accommodated by variations in capacity utilization only if $\bar{u}_{n}-c<u<\bar{u}_{n}+c$. At $u=\bar{u}_{n} \pm c$, all adjustment is accommodated through the price channel by $\Delta \pi$.

${ }^{21}$ Note that the result generated here is associated with a one-firm model. It seems plausible to conjecture that in a multi-agent framework, in which many, heterogeneous firms display the satisficing behaviour described above, we are likely to observe $\bar{u}_{n i} \neq \bar{u}_{n j}$ and $c_{n i} \neq c_{n j}$ for any two forms $i, j$. The extent to which small variations between firms in $\bar{u}_{n i}$ and $c_{n i}$ create larger long-run variability in aggregate capacity utilization is a topic left to further research.
} 


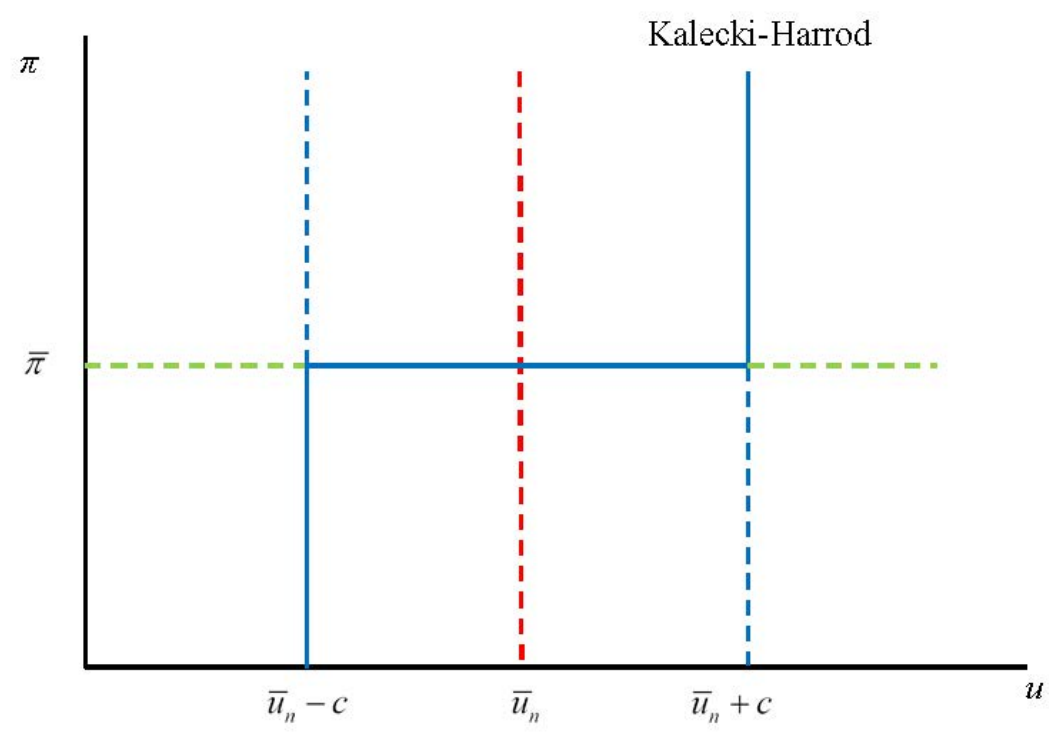

Figure 5: Kalecki-Harrod Growth Dynamics

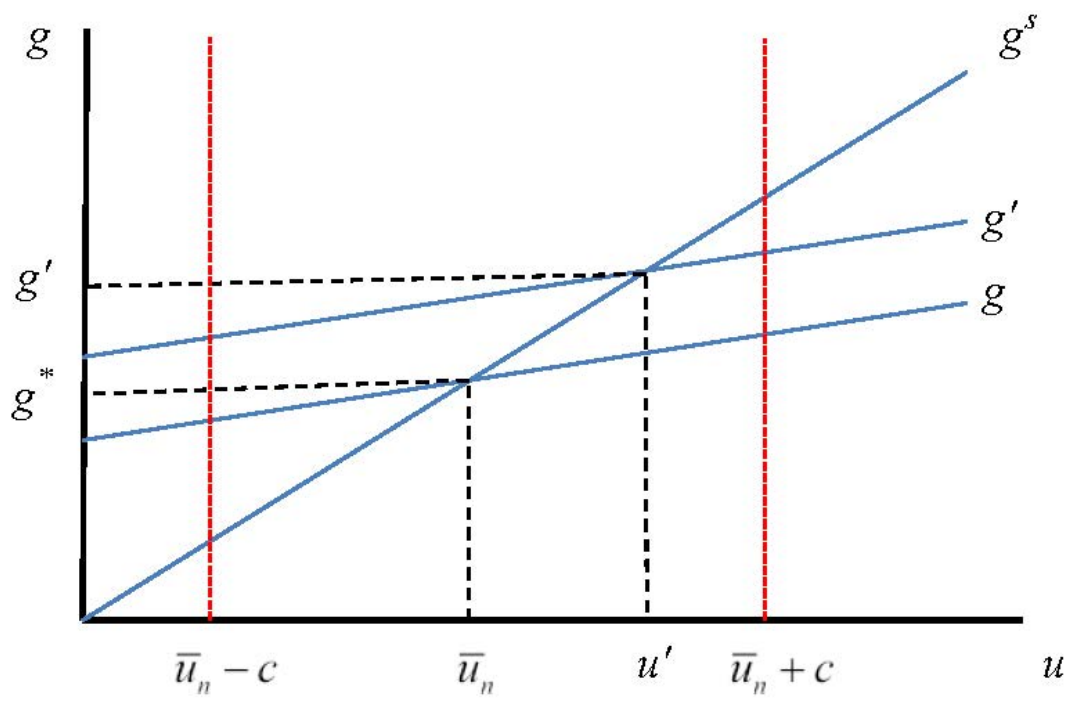

Figure 6: The Kalecki-Harrod Adjustment Mechanisms 


\section{On the value of $c$ in theory and practice: whither Harrodian instability?}

\subsection{A one-sector approach}

The analysis in the previous section is predicated on the existence of $c>0$, but provides no account of how, exactly, $c$ is determined and hence of its likely size relative to observed variations in the rate of capacity utilization. It is clear, however, that $c$ is a product of decision making under uncertainty, as a result of which firms' investment decisions rely on a satisficing heuristic that involves treating some range of variation in $u$ as "normal". As such, only abnormal variations elicit the sort of behavioural response that results in Harrodian instability. If the precise characteristics of the external environment are unknown (and unknowable) due to fundamental uncertainty, then following Keynes (1936), it can be assumed that firms will formulate a sense of "normal" variation in $u$ by reference to experience of the recent past and the thinking of others. In a one sector model with a single "representative" firm, only the first source of information can be considered, suggesting that the value of $c$ is linked to some measure of observed variation in $u$ in the recent past. To capture this, we postulate that:

$$
c=f\left(\sigma_{u}\right)
$$

where $\sigma_{u}$ denotes the standard deviation of the actual capacity utilization rate. Although $f($.$) is not observable, if the distribution of u$ is assumed Gaussian, so that $68 \%$ of values

of $u$ lie within one standard deviation of its mean, and if we postulate that firms treat this range of values as the "normal" range of variation in $u$ (that is deemed un-exceptional and merits no immediate behavioural response), then we have: 


$$
c=f\left(\sigma_{u}\right)=\sigma_{u}
$$

Assuming that $c$ is determined as in equation (14) and using monthly US aggregate capacity utilization data from 1990-2007, ${ }^{22}$ we find that $c=\sigma_{u}=3.18$. Using a Hodrick-Prescott filter to identify the trend value of $u, u_{T}$, and postulating that $u_{n}=u_{T}{ }^{23}$ the "corridor" within which $u$ can vary in the long run without eliciting changes in investment behaviour can be calculated as $u_{n} \pm c=u_{T} \pm \sigma_{u}$. Figure 7 plots this information, together with the actual value of the aggregate capacity utilization rate in the US 1990-2007. Figure 7 suggests that few of that actual variations in capacity utilization 1990-2007 fell outside the calculated "normal" range of variation in $u$, suggesting that little of the actual variation in $u$ 1990-2007 would likely have triggered the sort of investment response required to generate Harrodian instability.

It may, of course, be argued that our statistical definition of $u_{n} \pm c$ as $u_{T} \pm \sigma_{u}$ is too liberal. Suppose, instead, that firms' investment behaviour is impervious to variations in $u$ that fall within one-half of one standard deviation of the calculated normal value of $u .24$ Figure 8 repeats the exercise reported in Figure 7 , but this time operationalizing the range of "normal" values of $u$ as $u_{n} \pm c=u_{T} \pm 0.5 \sigma_{u}$. While (inevitably) more of the data falls outside this band, inspection of Figure 8 still suggests that little of the observed variation in capacity utilization in the US 1990-2007 would have triggered the investment response associated with Harrodian instability. Although the empirics presented in Figures 7 and

\footnotetext{
${ }^{22}$ The data in question are taken from the Federal Reserve database (FRED). Attention is confined to the period 1990-2007 for two reasons. First, this period coincides with the neoliberal long-wave upswing in the US, a distinct stage of US capitalism during which the institutional structure of the US economy - including the "normal" range of variation of $u$ central to the present analysis - can reasonably be conceived as both established and stable. Second, evidence suggests that the rate of capacity utilization in the US exhibits a negative time-trend over the post-1948 period as a whole (Blecker, 2016). To the extent that the rate of capacity utilization is non-stationary over long intervals of time, this will affect the calculation of $\sigma_{u}$ used to infer the "normal" range of variation in $u$.

${ }^{23}$ See, for example, Skott (2012, p.132).

${ }^{24}$ Recall that $38 \%$ of the values of a normal distribution fall within one half of one standard deviation of the mean of the distribution.
} 


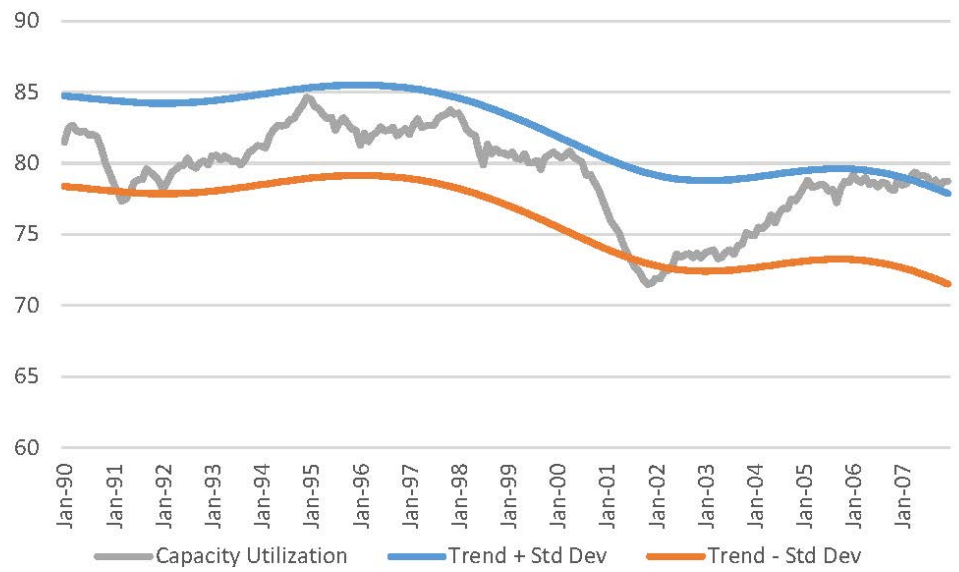

Figure 7: Actual Variations In, and the Acceptable Range Of, US Capacity Utilization Rates, 1990-2007

8 are not in any sense conclusive, what they suggest is that the conditions that generate Harrodian instability are the exception rather than the rule 25

\subsection{A multi-industry analysis}

\subsubsection{Re-casting the model in multi-industry form}

Advanced capitalist economies are, of course, made up of more than one sector, and each sector comprises multiple heterogeneous industries. These industries may have different normal rates of capacity utilization, experience different levels of volatility in their actual capacity utilization rates, and may therefore develop different tolerances for variation in the rate of capacity utilization before seeing fit to respond by changing their investment behaviour. If we retain the approach to modelling $c$ described in equation (14) as representative for individual industries ${ }^{26}$ we can take all this into account by using industry-level US data to

\footnotetext{
${ }^{25}$ See also Trezzini (2016).

${ }^{26}$ Note that we could now make inter-industry comparisons a feature of each industry-specific calculation of $c$, but abstract from this possibility for the sake of simplicity.
} 


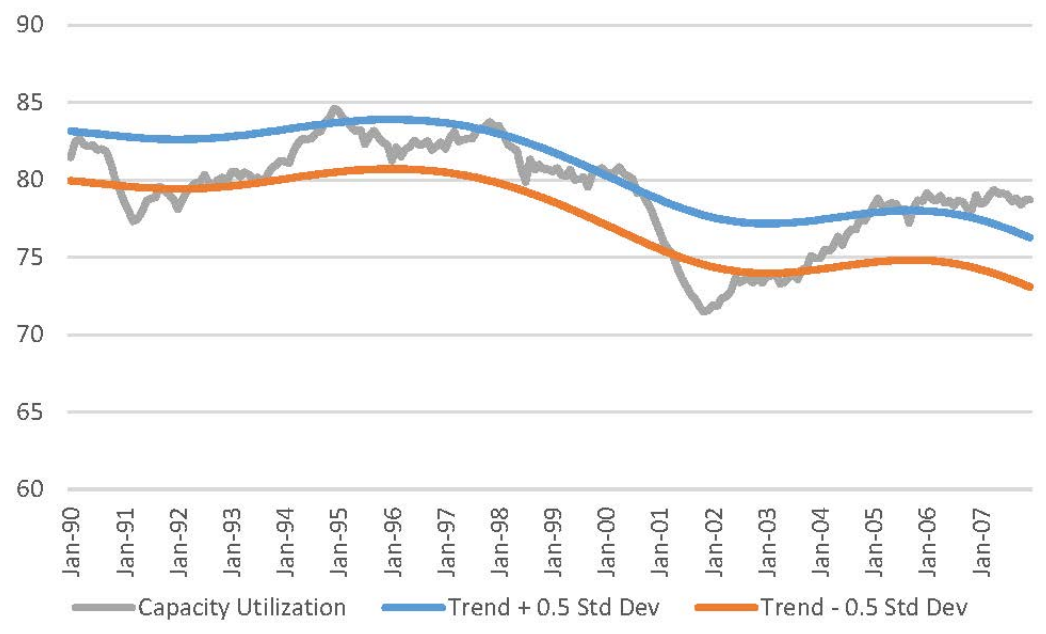

Figure 8: Actual Variations In, and the Acceptable Range Of, US Capacity Utilization Rates, 1990-2007: A More Conservative Approach

describe the behaviour of individual industries, and deriving aggregate properties from the combined behaviour of individual industries 27

To this end, consider the ith industry, in which:

$$
\begin{gathered}
\dot{g}_{i}=0 \text { if }\left|u_{i}-\bar{u}_{n i}\right|<c_{i} \\
\dot{g}_{i}=\left(u_{i}-\bar{u}_{n i}\right) \text { otherwise }
\end{gathered}
$$

This implies that:

$$
\Delta u_{i}=\frac{1}{\left(s_{\pi}-\gamma_{2}\right) \bar{\pi}} \Delta \gamma_{1}
$$

if $\bar{u}_{n i}-c_{i}<u_{i}<\bar{u}_{n i}+c_{i}$, or:

\footnotetext{
${ }^{27}$ The precise data used in what follows are described in Appendix A.
} 


$$
\Delta \pi_{i}=\frac{1}{\left(s_{\pi}-\gamma_{2}\right) u_{B i}} \Delta \gamma_{1}
$$

where $u_{B i}=\bar{u}_{n i} \pm c_{i}$.

For any industry $i$, and again using data for the period 1990-2007 (coinciding with the neoliberal long-wave upswing), we set $\bar{u}_{n i}=\mu_{u_{i}}$ and $c_{i}=\sigma_{u_{i}}$. We set $s_{\pi}=0.8, \gamma_{1}=2.25$, and $\gamma_{2}=0.72$, a constellation of parameter values that together ensures that $\bar{\pi}=0.33$ in our one sector model. We then set $\bar{\pi}_{i}=\bar{\pi} \quad \forall i$. Starting from an initial value of $\bar{u}_{n}=\sum_{i=1}^{n} \kappa_{i} \bar{u}_{n i}$, and for successive increments/decrements in $\gamma_{1}$ of size $\left|\Delta \gamma_{1}\right|=0.005$, we calculate:

$$
\Delta u=\sum_{i} \kappa_{i} \Delta u_{i}
$$

and:

$$
\Delta \pi=\sum_{i} \rho_{i} \Delta \pi_{i}
$$

where $\kappa_{i}=K i / K$ is approximated by the relative importance weight (RIW) attached to each industry in the FRED data base. ${ }^{28}$ Finally, we calculate:

$$
u=u_{-1}+\Delta u
$$

and:

$$
\pi=\pi_{-1}+\Delta \pi
$$

\footnotetext{
${ }^{28}$ Again, the reader is referred to Appendix $\mathrm{A}$ for a fuller description of our data.
} 


\subsubsection{Results}

The results of the calculations described in equations (15) and (16) are reported in Figure 9 and Table 1. Figure 9 illustrates simulated long-run variation in aggregate capacity utilization arising from industry-specific variation in long-run capacity utilization, while Table 1 reports the range of values $\bar{u}_{n} \pm c$ illustrated in Figure 9 , together with the actual minimum and maximum values of US aggregate capacity utilization data 1990-2007, and the minimum and maximum values that lie within a three standard deviation range of the mean of US aggregate capacity utilization data $1990-2007{ }^{29}$ Note that ranges reported in Table 1 for $c_{i}=\sigma_{u_{i}}\left(\right.$ and $\left.c_{i}=0.5 \sigma_{u_{i}}\right)$ are the extreme values at which all industries turn to "Robinsonian" adjustment - i.e., points at which the entire economy can be considered as adjusting in neo-Keynesian fashion (although some individual industries may have taken recourse to this mode of adjustment before these extremes have been reached). What we see is that with $c_{i}=\sigma_{u_{i}}$, the range of $u$ within which we observe Kaleckian adjustment accounts for $63 \%$ of the observed range of the data and $43 \%$ of the plausible (mean plus or minus 3 standard deviations) range. Figure 9 illustrates the range of long-run variation in aggregate capacity utilization when the simulation exercise is repeated with $c_{i}=0.5 \sigma_{u_{i}}$. As is evident from Table1, with $c_{i}=0.5 \sigma_{u_{i}}$, the range of $u$ within which we observe Kaleckian adjustment now accounts for $33 \%$ of the observed range of the data and $22 \%$ of its plausible (mean plus or minus 3 standard deviations) range.

These findings offer a different perspective on the issue addressed in Figures 7 and 8 . what is the range of observed values of aggregate capacity utilization that might be regarded as "normal", in so far as they do not excite economy-wide changes in investment behaviour of the sort associated with the onset of Harrodian instability? Once again this range seems to be large, relative to either the observed range of capacity utilization rates 1990-2007, or the

\footnotetext{
${ }^{29}$ Recall that over $99 \%$ of the values of a normally distributed variable lie within three standard deviations of its mean.
} 


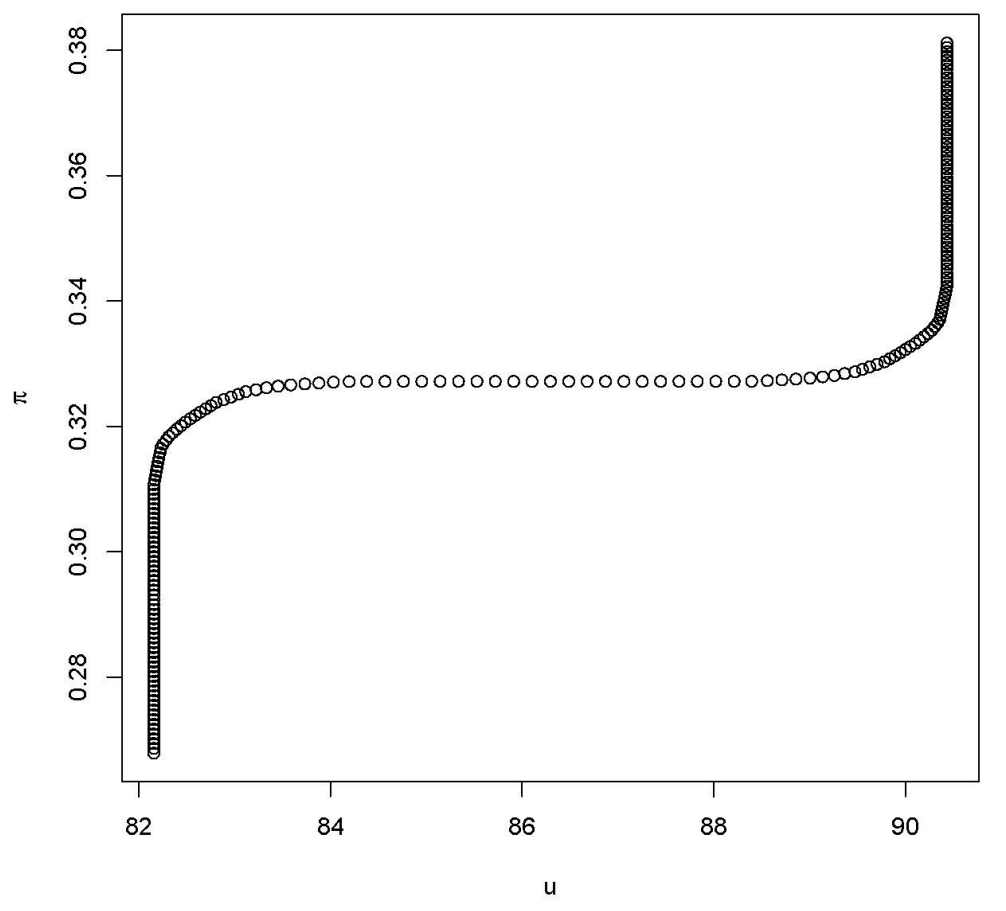

Figure 9: The Kalecki-Harrod Adjustment Mechanism: A Multi-Industry Simulation $\left(c_{i}=\right.$ $\left.\sigma_{i}\right)$ 


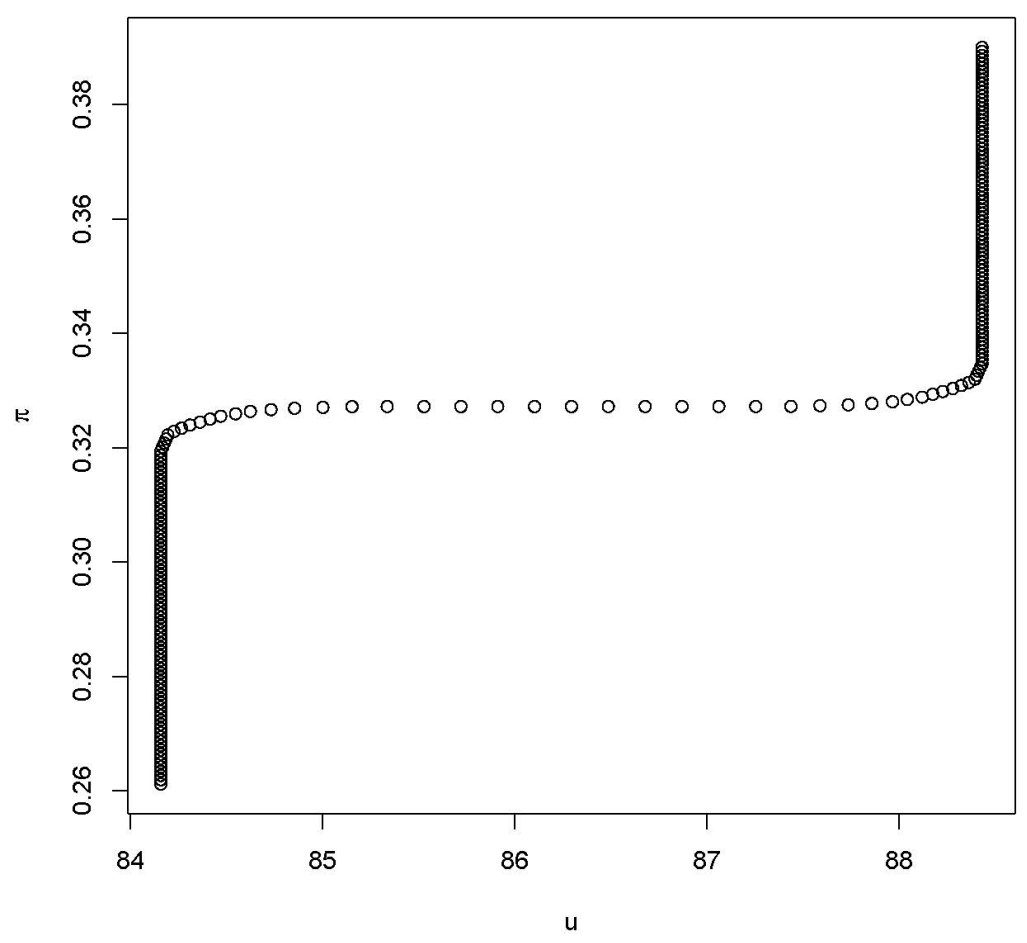

Figure 10: The Kalecki-Harrod Adjustment Mechanism: A Multi-Industry Simulation $\left(c_{i}=\right.$ $\left.\sigma_{i}\right)$ 
Table 1: Actual and Simulated Minimum and Maximum Values of $u$

\begin{tabular}{lll}
\hline & $u_{\min }$ & $u_{\max }$ \\
\hline & & \\
$u$ & 71.48 & 84.62 \\
$c_{i}=\sigma_{u_{i}}$ & 82.16 & 90.43 \\
$c_{i}=0.5 \sigma_{u_{i}}$ & 84.16 & 88.43 \\
$\mu_{u} \pm 3 \sigma_{u}$ & 69.84 & 88.75 \\
& & \\
\hline
\end{tabular}

statistically feasible range of such variation (based on the assumptions that have been made about the distribution of $u$ ). Bearing in mind that both the observed and statistically feasible ranges are calculated using extrema, and that the frequency with which these extrema are realized appears to be rare (judging by the evidence presented in Figures 7 and 8 , and the likelihood of observing an outcome at a distance of three standard deviations from the mean of a normal distribution), the conclusion that once again emerges is that the conditions responsible for generating Harrodian instability are more the exception than the rule.

\section{Conclusion}

This paper develops a generic Kalecki-Robinson model of growth that, subject to different closures, illustrates how the economy can respond, through either price- or quantity-adjustment channels, to a change in demand conditions in the long run. The closures have different implications for the actual rate of capacity utilization, and hence what (if anything) is required by way of additional adjustments if the economy is to achieve a "fully-adjusted position" where the actual and normal rates of capacity utilization are equalized. Next, it is assumed that the normal rate of capacity utilization is exogenously fixed. It is then shown that variation in the actual capacity utilization rate can nevertheless occur - at least within limits - without triggering "Harrodian instability", if the response of investment to discrepancies 
between the actual and normal rates of capacity utilization is discontinuous.

The behavioural argument advanced in support of the discontinuous investment function has a Harrodian pedigree, drawing on Harrod's own preferred treatment of his instability principle as being analogous to a "shallow dome" or "grassy slope" rather than a Solovian "knife edge". The argument therefore rests on a Harrodian interpretation of Harrodian instability. Put differently, the paper shows that it is the combination of (proper) Harrodian dynamics and Kaleckian dynamics that simultaneously becalms Harrodian instability - at least within the satisficing range of capacity utilization rates determined by $\bar{u}_{n} \pm c-$ and permits long run variability in the rate of capacity utilization despite the existence of a fixed normal rate.

The theory developed is then operationalized by appeal to standard assumptions about decision making under uncertainty and the statistical properties of Gaussian distributions. This permits statistical identification of the normal range of variation in capacity utilization that firms will deem tolerable, and that will not, therefore, elicit the changes in investment behaviour required to generate Harrodian instability. Both aggregate and industry-level US capacity utilization data are used to calculate several possible bands that represent this normal range of variation in the capacity utilization rate, and these bands are compared to both actual variations in capacity utilization and the feasible range of variation in capacity utilization (based on the statistical properties of the data). These calculations suggest that the circumstances under which Harrodian instability will materialize are likely to be relatively rare.

\section{A Data}

The raw data used for our numerical simulations are Federal Reserve Data (FRED) on the Capacity Utilization Rate and the Relative Importance Weight (RIW), which is a contribution to production index. Table 2 reports the mean and the standard deviation of the capacity utilization rate $\left(\mu_{u}\right.$ and $\sigma_{u}$, respectively), together with the mean of the RIW $\left(\mu_{R I W}\right)$, for 25 industries, 1990-2007. 
Table 2: Mean and Standard Deviation of $u$ and Mean of RIW for 25 Industries, 1990-2007

\begin{tabular}{lccc}
\hline & $\mu_{u}$ & $\sigma_{u}$ & $\mu_{R I W}$ \\
\hline & & & \\
Motor Vehicles and Parts & 81.85 & 6.20 & 5.08 \\
Electrical Equipment & 88.43 & 5.61 & 1.87 \\
Miscellaneous & 81.61 & 2.34 & 2.29 \\
Wood Product & 83.17 & 3.41 & 1.18 \\
Non-metalic Mineral Product & 82.20 & 4.64 & 1.74 \\
Furniture and Related Product & 81.51 & 4.11 & 1.27 \\
Computer and Electronic Product & 80.91 & 6.42 & 7.35 \\
Fabricated Metal Product & 83.09 & 4.20 & 4.50 \\
Machinery & 82.22 & 5.86 & 4.52 \\
Primary Metal & 87.43 & 5.62 & 2.20 \\
Transportation Equipment & 80.05 & 3.36 & 8.06 \\
Chemical & 82.87 & 3.03 & 8.24 \\
Printing and Related Support Activities & 84.76 & 4.22 & 1.98 \\
Textiles and Product & 84.83 & 5.90 & 1.20 \\
Petroleum and Coal Product & 94.55 & 3.31 & 1.64 \\
Apparel and Leather Goods & 82.48 & 5.57 & 1.16 \\
Food, Beverage and Tobacco & 85.16 & 2.82 & 8.42 \\
Plastics and Rubber Products & 88.83 & 4.51 & 2.80 \\
Paper & 90.79 & 3.22 & 2.49 \\
Oil and Gas Extraction & 98.11 & 1.99 & 3.93 \\
Computers, Communications Equipment, and Semiconductors & 82.28 & 7.89 & 4.98 \\
Electric Power Generation, Transmission, and Distribution & 95.41 & 3.88 & 6.55 \\
Mining & 93.23 & 2.48 & 6.10 \\
Crude Processing & 92.23 & 2.20 & 9.40 \\
Natural Gas Distribution & 83.70 & 4.20 & 1.05 \\
& & & \\
\hline
\end{tabular}




\section{References}

Asimakopulos, A. (1991). Keynes's General Theory and Accumulation. Cambridge: Cambridge University Press.

Auerbach, P. and P. Skott (1988). Concentration, competition and distribution - a critique of theories of monopoly capital. International Review of Applied Economics 2(1), 42-61.

Barba, A. and M. Pivetti (2009). Rising household debt: Its causes and macroeconomic implications - a long-period analysis. Cambridge Journal of Economics 33(1), 113-137.

Blecker, R. (2016). Wage-led versus profit-led demand regimes: the long and the short of it. Review of Keynesian Economics 4(4), 373-390.

Brown, C. (2008). Inequality, Consumer Credit and the Saving Puzzle. Cheltenham: Edward Elgar.

Cassetti, M. (2006). A note on the long-run behaviour of Kaleckian models. Review of Political Economy 18(4), 497-508.

Commendatore, P. (2006). Are Kaleckian models relevant for the long run? In N. Salvadori and C. Panico (Eds.), Classical, Neoclassical and Keynesian Views on Growth and Distribution. Cheltenham: Edward Elgar.

Committeri, M. (1986). Some comments on recent contributions on capital accumulation, income distribution and capacity utilization. Political Economy 2(2), 161-86.

Cynamon, B. Z. and S. M. Fazzari (2008). Household debt in the consumer age: Source of growth - risk of collapse. Capitalism and Society $3(2)$.

Dallery, T. and T. van Treeck (2011). Conflicting claims and equilibrium adjustment processes in a stock-flow consistent macroeconomic model. Review of Political Economy 23(2), 189-211.

Dequech, D. (1999). Expectations and confidence under uncertainty. Journal of Post Keynesian Economics 21(3), 415-430.

Dutt, A. K. (1990). Growth, Distribution and Uneven Development. Cambridge: Cambridge University Press.

Dutt, A. K. (1997). Equilibrium, path dependence and hysteresis in post-Keynesian models. In P. Arestis, G. Palma, and M. Sawyer (Eds.), Capital Controversy, Post-Keynesian Economics and the History of Economic Thought: Essays in Honour of Geoff Harcourt. London: Routledge.

Dutt, A. K. (2009). Path dependence, equilibrium and economic growth. In P. Arestis and M. Sawyer (Eds.), Path Dependency in Macroeconomics: International Papers in Political Economy. Houndmills and New York: Palgrave. 
Dutt, A. K. (2010). Equilibrium, stability and path dependence in Post Keynesian models of economic growth. In A. Birolo, D. Foley, H. D. Kurz, B. Schefold, and I. Steedman (Eds.), Production, Distribution and Trade: Alternative Perspectives. Essays in Honour of Sergio Parrinello. London: Routledge.

Flaschel, P., R. Franke, and W. Semmler (1997). Dynamic Macroeconomics: Instability, Fluctuations and Growth in Monetary Economics. Cambridge, MA,: MIT Press.

Franke, R. (2015). An examination of Professor Shaikh's proposal to tame Harrodian instability. European Journal of Economics and Economic Policies: Intervention 12(1), $7-19$.

Halsmayer, V. and K. D. Hoover (2015). Solow's Harrod: Transforming macroeconomic dynamics into a model of long-run growth. The European Journal of the History of Economic Thought DOI: 10.1080/09672567.2014.1001763.

Harrod, R. (1939). An essay in dynamic theory. Economic Journal 49(193), 14-33.

Harrod, R. F. (1948). Towards a Dynamic Economics. London: Macmillan.

Harrod, R. F. (1970). Harrod after twenty-one years: a comment. Economic Journal 80(319), $737-41$.

Harrod, R. F. (1973). Economic Dynamics. London: Macmillan.

Hein, E., M. Lavoie, and T. van Treeck (2011). Some instability puzzles in Kaleckian models of growth and distribution: a critical survey. Cambridge Journal of Economics 35(3), $587-612$.

Hein, E., M. Lavoie, and T. van Treeck (2012). Harrodian instability and the 'normal rate' of capacity utilization in Kaleckian models of distribution and growth - a survey. Metroeconomica 63(1), 139-169.

Hicks, J. (1974). The Crisis in Keynesian Economics,. Oxford: Basil Blackwell.

Keynes, J. M. (1936). The General Theory of Employment, Interest and Money. London: Macmillan.

Kregel, J. (1980). Economic dynamics and the theory of steady growth: An historical essay on Harrod's 'knife-edge'. History of Political Economy 12(1), 97-123.

Lavoie, M. (1992). Foundation of Post-Keynesian Economic Analysis. Cheltenham, UK: Edward Elgar.

Lavoie, M. (1995). The Kaleckian model of growth and distribution and its Neo-Ricardian and Neo-Marxian critiques. Cambridge Journal of Economics 19(6), 789-818. 
Lavoie, M. (1996). Traverse, hysteresis and normal rates of capacity utilization in kaleckian models of growth and distribution. Review of Radical Political Economics 28(4), 113-147.

Lavoie, M. (2002). The Kaleckian growth model with target return pricing and conflict inflation. In M. Setterfield (Ed.), The Economics of Demand-led Growth. Cheltenham: Edward Elgar.

Lavoie, M. (2003). Kaleckian effective demand and Sraffian normal prices: Towards a reconciliation. Review of Political Economy 15(1), 53-74.

Lavoie, M. (2010). Surveying short-run and long-run stability issues with the Kaleckian model of growth. In M. Setterfield (Ed.), Handbook of Alternative Theories of Economic Growth,. Cheltenham, UK: Edward Elgar.

Palley, T. I. (2002). Economic contradictions coming home to roost? does the us economy face a long-term aggregate demand generation problem? Journal of Post Keynesian Economics 25, 9-32.

Palumbo, A. and A. Trezzini (2003). Growth without normal capacity utilization. The European Journal of the History of Economic Thought 10(1), 109-135.

Robinson, J. (1956). The Accumulation of Capital. London: Macmillan.

Robinson, J. (1962). Essays in the Theory of Economic Growth. London and Basingstoke: Macmillan.

Robinson, J. (1970). Harrod after twenty-one years. Economic Journal 80(319), 731-37.

Schoder, C. (2012). Hysteresis in the Kaleckian growth model: A Bayesian analysis for the US manufacturing sector from 1984 to 2007. Metroeconomica 63(3), 542-568.

Setterfield, M. (2013). Wages, demand and us macroeconomic travails: Diagnosis and prognosis. In B. Z. Cynamon, S. M. Fazzari, and M. Setterfield (Eds.), After the Great Recession: The Struggle for Economic Recovery and Growth, pp. 158-184. Cambridge University Press.

Setterfield, M. (2015). Time variation in the size of the multiplier: a Kalecki-Harrod approach. Working Papers 1522, New School for Social Research, Department of Economics.

Shaikh, A. (2009). Economic policy in a growth context: a classical synthesis of Keynes and Harrod. Metroeconomica 60(3), 455-494.

Simon, H. (1955). A behavioral model of rational choice. Quarterly Journal of Economics 69(1), 99-118.

Simon, H. (1956). Rational choice and the structure of the environment. Psychological Review 63, 129-138. 
Skott, P. (2010). Growth, instability and cycles: Harrodian and Kaleckian models of accumulation and income distribution. In M. Setterfield (Ed.), Handbook of Alternative Theories of Economic Growth. Cheltenham: Edward Elgar.

Skott, P. (2012). Theoretical and empirical shortcomings of the Kaleckian investment function. Metroeconomica 63(1), 109-138.

Skott, P. and S. Ryoo (2008). Macroeconomic implications of financialisation. Cambridge Journal of Economics 32(6), 827-862.

Solow, R. M. (1956). A contribution to the theory of economic growth. Quarterly Journal of Economic 70(1), 65-94.

Trezzini, A. (2016). Harrodian instability: a misleading concept. Universitá di Roma Tre, mimeo.

Wisman, J. D. (2013). Wage stagnation, rising inequality and the financial crisis of 2008. Cambridge Journal of Economics 37, 921-945. 